\title{
Effects of Satureja Edmondi Briq on Ameliorate Reproductive Parameters in Pentylenetetrazol- Induced Epilepsy Models in Rats
}

somayeh bohlouli ( $\sim$ sbohloli@yahoo.com )

kermansh brunch, islamic azad university, kermanshah, iran. https://orcid.org/0000-0003-0854-1875 gelavij mahmoodi

kermanshah brunch, islamic azad university, kermanshah, iran

\section{Research}

Keywords: Epilepsy, Saturejae dmondiBriq, fertility, reproductive parameters, rat

Posted Date: October 20th, 2020

DOI: https://doi.org/10.21203/rs.3.rs-93397/v1

License: (c) (1) This work is licensed under a Creative Commons Attribution 4.0 International License.

Read Full License 


\section{Abstract}

\section{Background}

Epilepsy is one of the common neurological brain defects that causes unpredictable, recurrent seizures. It has adverse effects on the reproductive functions. Oxidative stress contributes to the evolution of epilepsy, including reduction of sperm count and motility,increase of abnormal sperm morphology, and low testosterone.Antioxidants are beneficial to spermatogenesis and sperm parameters. Satureja edmondiBriq is known as a powerful antioxidant that can reduce the effects of oxidative stress. The aim of this study was to evaluate the effects of Satureja edmondion reproductive potential in pentylenetetrazol (PTZ)-induced epileptic male rats.

\section{Methods}

In this experimental study, 48 Wistar male rats with an average age of 10 weeks and weightof $240-260 \mathrm{~g}$ were used. Animals were randomized into normal and kindled groups that were treated with different doses of S.edmondi essential oil. Treatment of animals lasted 4 weeks. In the end, testosterone, folliclestimulating hormone, luteinizing hormone, and sperm parameters were measured according to the World Health Organization (WHO) standards.

Results

This study showed that all sperm parameters,including sperm count, sperm viability, and progressive sperm motility were increased and testosterone, follicle-stimulating hormone and luteinizing hormone $(\mathrm{FSH}, \mathrm{LH})$ changes in the epileptic and normal groups were changed with an increase in the dose of S.edmondi essential oil.

\section{Conclutions}

The changes were significant in some parameters. S.edmondi as a good source of antioxidants can improve sperm parameters and reproductive potential in PTZ-induced epileptic male rats.

\section{Introduction}

Epilepsy is one of the most common central nervous system disorders after stroke that affects the people's lives.It is caused by the unusual electrical activities in the brain. Epilepsy is determined by uncontrolled and recurrent seizures that disruptbrain activity and mental and physical functions [1]. Continuousseizures for at least 30 minutes and discontinuous seizures shorter than 30 minutes (even 5 $\mathrm{min}$ ) are defined as status epilepticus [2]. Seizure symptoms are variablefrom person to person.

Epilepsy can cause periods of unusual behavior, uncontrollable movementofarms and legs, and sometimes loss of awareness.Epilepsy has an impact on the reproductive system [3]. Epilepsy also influences the pituitary-gonadal hormone and reproductive parameters. Sexual dysfunction and fertility 
problems have been noted in men with epilepsy [4]. Reproductive impairment is attributed both to epilepsy itself and antiepileptic drugs (AEDs) [5]. Epilepsy,antiepileptic drugs (AEDs), and the reproductive system haveintricateinteractions [6]. Reproductive endocrine dysfunction is unusually common among women and men with epilepsy.Epilepsy has negative effects on the male reproductive system in epileptic patients and animals.

Pentylenetetrazol(PTZ) is a chemical that stimulates seizure in the central nervous systemand is used as a convulsing drug in experimental studies. It is the most preferred and common drug for kindling [7].Oxidative stress is considereda possible mechanism involved in epileptogenesis. Experimental studies have pointed outthat oxidative stress is a contributing factor to the onset and evolution of epilepsy [8].

some plants are regarded as powerful antifungal, antimicrobial and antioxidant since ancient times.

An antioxidant can be broadly defined as any substance that delays or inhibits oxidative damage to a target molecule.Antioxidant compounds scavenge free radicals $[9,10]$.Many herbs are known to have antioxidant effects on the growth and immunological parameters in some animals $[11,12]$.

The essential oil of S. edmondi contains predominant compounds like thymol, gamma terpinene, andpCymene. These compounds are known to have antimicrobial, antifungal, anti-inflammatory, and specially antioxidant properties[13]. In our previous study, we observed the positive effect of S.edmondi on memory impairment induced by chemical kindling in male rats[14]. This study was conducted to investigate the link between chemical kindlingand positive effect of $S$. edmondion the reproductive parameters and pituitary-gonadal hormone in epileptic male rats.

\section{Materials And Methods}

\section{Animals}

A total of 48 Wistar male rats $(240-260 \mathrm{~g})$ were purchased from Razi Institute (Tehran, Iran) and housed under controlled environmental conditions, $12 / 12 \mathrm{~h}$ light/dark cycle and $22 \pm 2 \mathrm{C}^{\circ}$ temperature. Food and water were freely available throughout the study. The rats were kept in the laboratory one week before the start of the experiment so that they could adapt to the environment. The experiment protocol was approved by the ethics committee of animal research (IR.KUMS.REC.1398.977).

\section{Preparation of plant}

Satureja edmondiBriq was obtained from the mountains of Kermanshah, Iran. It was identified and authenticated by the herbarium of Islamic Azad University of Kermanshah. Essential oil extraction was performed by steam distillation and a Clevenger-type apparatus [13].

\section{Experimental design}


The rats were randomly divided into control,kindling, and treatment groups ( 6 groups of 8 rats)and treated for 28 days:

Group 1: Normal control group

Group 2: Normal control group received 150ppm essential oil

Group 3: Normal control groupreceived 300ppm essential oil

Group 4:Kindled control group

Group 5:Kindled group receiving 150ppm essential oil

Group 6:Kindled group receiving 300ppm essential oil

All efforts were made to minimize the number of animals and their suffering. Treatment groups were kindled by repetitive intraperitoneal injection of PTZ( $25 \mathrm{mg} / \mathrm{kg}$ bodyweight) (Sigma, St. Louis, MO, USA) every 15 minutes until seizure occurred (two or three injections) [15].Seizure activity was observed for 45. The rats reaching phase 4 or 5 were considered kindled rats. PTZ was administered intraperitoneally in a single dose every other day tothe kindled and normal groups receivingdifferent doses of essential oil. Control groups were recipient of normal saline. All experiments werecarried out in the morning. At the end of the treatments, the animals were anesthetized with ketamine $2.5 \mathrm{mg} / \mathrm{kg})$ and xylazine (30 $\mathrm{mg} / \mathrm{kg}$ ). Then, blood samples were taken fromthe heart and serum was separated by centrifuge (3000 $\mathrm{RPM}, 20 \mathrm{~min})$. To measure the hormones level, the serum samples were kept in the freezer at $-20^{\circ} \mathrm{C}$.

\section{Semen analysis}

After anesthesia was conducted and blood was the taken from heart, cauda epididymis was separated and cut in Hams/f10 including $10 \%$ FBS and was kept in an incubator $\left(37^{\circ} \mathrm{C}\right.$ and $\left.5 \% \mathrm{CO} 2\right)$ for thirty minutes. The prepared suspension was used for the analysis of sperm parameters such as sperm viability, motility, and count. The suspensionwas pipetted into the counting chamber and immediately assessed for sperm count and motility. The sperm heads on the four corners of the central square of Neubauer slide were counted, and data were expressed as the number of sperm per ml.To assess viability, a drop of semen was placed on a slideand stained with Eosin-Nigrosin'sdye. The none-stained sperms were expressed as viable sperms.Non-viable spermshad red or dark-pink heads and viable spermshad white or faintly-pink heads. Testosterone and pituitary-gonadal hormone $(\mathrm{FSH}, \mathrm{LH})$ levels were measured by the ELISA kite and plasma-optical emission spectroscopy(EUROIMMUN Analyser I-2P) [16].

\section{Statistical analysis}

The results were statistically estimated by one-way analysis of variance (ANOVA) and were presented as Mean \pm SEM. Additional analysis for multiple comparisons was carried outby post-hoc Tukey test. In all evaluations, $p<0.05$ was considered statistically significant. 


\section{Results}

The results of changes in sperm count, sperm viability, and progressive sperm motility in normal groups are presented in Table 1 and those of kindled groups are shown in Table2. According to the results of this study, these parameters increased in the group that

received150 ppm Satureja edmondi Briq essential oil compared to the normal control group, but this increase was not significant. The group that received 300 ppm S.edmondiessential oil showed a statistically significant increasein these parameters compared to the control group $(p \leq 0.001)$.

Moreover, these variables indicated a significant decrease in the kindled group compared to the control group ( $\mathrm{p} \leq 0.001)$. Further, these variables increased significantly in the kindled groups receiving the 150 $\mathrm{ppm}$ and $300 \mathrm{ppm}$ doses compared to the kindled control group $(\mathrm{p} \leq 0.001)$. The results of testosterone measurement $(\mathrm{ng} / \mathrm{ml})$ in the normal group showed that this variable increased in the group that receiving S.edmondi essential oil with $150(2.28 \pm 0.08)$ and $300(2.51 \pm 0.07)$ doses compared to the control group(2.08 \pm 0.08$)$, but this increase was not significant.

On the other hand, this variable indicated a significant decreasein the kindled group $(0.99 \pm 0.03)$ compared to the normal control group $(\mathrm{p} \leq 0.001)$. Also, the comparison between the kindled groups receiving the $300 \mathrm{ppm}$ and $150 \mathrm{ppm}$ doses of S.edmondi essential oil andkindled control group showed an increase in testosterone levels. This increase was significant with $300 \mathrm{ppm}$ dose $(\mathrm{p} \leq 0.001)$ (Figure 1). The LH hormone (mlu / ml) increased in normal groups that received $150 \mathrm{ppm}$ S.edmondi essential oil (1.36 \pm 0.88$)$ compared to the control group (1.06 \pm 0.88$)$;however, this increase was not significant.

Further, this variable significantly increased in the group that received $300 \mathrm{ppm}$ S.edmondi essential oil (1.65 \pm 0.77$)$ compared to the control group $(1.06 \pm 0.08)(P \leq 0.001)$. On the other hand, this variable indicated a significant decrease in the PTZ receptor group $(0.05 \pm 0.03)$ compared to the normal control group ( $0.6 \pm 0.08)(p \leq 0.001)$. Moreover, the comparison between kindled groups receiving 300 and 150 doses of S.edmondi essential oil and kindled control group showed an increase in the LH levels. This increase was significant with $300 \mathrm{ppm}$ dose ( $\mathrm{p} \leq 0.001)$ (Figure 2).

Changes in FSH levels ( $\mathrm{mlu} / \mathrm{ml}$ ) in the groups are shown in Figure 3. This variable increased in normal groups that received different doses of S.edmondiessential oil compared to the normal control group, but this increase was not statistically significant. This variable decreased significantly in the kindled group compared to the normal control group $(p \leq 0.01)$. Moreover, the comparison of this variable between thekindled groups receiving different doses of S.edmondiessential oil andkindled control group did not show a significant difference.

Table1. The effect of SaturejaedmondiBriq essential oil on sperm parameters in normal groups.

the data are expressed as Mean \pm SE. In comparison with control group significant differences are shown by $* \star * p \leq 0.001$ 


\begin{tabular}{|llll|}
\hline \multicolumn{4}{|c|}{ Difference of Satureja edmondiBriq essential oil in normal rats } \\
\hline & Control & $150 \mathrm{ppm}$ & $300 \mathrm{ppm}$ \\
\hline $\begin{array}{l}\text { Sperm count } \\
\left(\times 10^{6}\right)\end{array}$ & $64.5 \pm 1.1$ & $67.3 \pm 0.76$ & $71.83 \pm 0.79 * *$ \\
\hline Viability (\%) & $72.3 \pm 3.8$ & $75 \pm 0.57$ & $79.3 \pm 0.61$ \\
\hline High motility (\%) & $61.5 \pm 0.96$ & $64 \pm 0.84$ & $69.6 \pm 0.84 * * *$ \\
\hline
\end{tabular}

Table 2. The effect of Satureja edmondi Briq essential oil on sperm parameters in kindle groups.

the data are expressed as Mean \pm SE.In comparison with control group significant differences are shown by $* \star \star p ~ \leq 0.001$

\begin{tabular}{|c|c|c|c|}
\hline \multicolumn{4}{|c|}{ Difference of SaturejaedmondiBriq essential oil in kindle rats } \\
\hline Sperm parametr & Control & 150ppm & 300ppm \\
\hline $\begin{array}{l}\text { Sperm count } \\
\left(\times 10^{6}\right)\end{array}$ & $41.6 \pm 1.05$ & $46 \pm 0.57 * \star \star$ & $52.6 \pm 0.88 * \star \star$ \\
\hline Viability (\%) & $41.2 \pm 1.2$ & 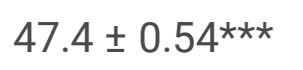 & $58.6 \pm 0.85^{\star \star \star}$ \\
\hline High motility (\%) & $42 \pm 0.84$ & $47.08 \pm 0.53^{\star \star *}$ & $59.6 \pm 0.67 * \star \star$ \\
\hline
\end{tabular}

\section{Discussion}

Fertility is lower in both men and women with epilepsy than in the general population. Moreover, reproductive endocrine disorders are more common among patients with epilepsy than thegeneral population. In this study, all sperm parameters such as sperm count, sperm viability, progressive sperm motility, and testosterone and pituitary-gonadal hormone changesin the epileptic and normal groups were changed by increasing the dose of Satureja edmondi Briq essential oil. The increase in these variables was significant in some instances. The total number of sperms, sperm viability, and progressive motility in both normal and epileptic groupswereraised with an increase inthe dose of Satureja edmondi Briq essential oil. Thus, the highest dose of S.edmondi essential oil increased significantly in normal groups compared to normal control group, and different doses of S.edmondi essential oil caused a significant increase in epileptic groups compared to the epileptic control group.

Previous studies have shown that most men with epilepsy have abnormal sperm parameters, including decreased sperm count, abnormal morphology, and impaired motility [17]. In a study, the antioxidant effects as well as the stimulating effects of Satureja Khuzestanica essential oil on fertility in male rats 
were investigated. The results showed the positive effects of Satureja Khuzestanica on fertility in male rats [18].In patients with epilepsy, sperm motility decreased and caused sperm abnormalities [19]. Focal epilepsy may affect the spermmorphology, concentration, and motility [20]. Induction of experimental epilepsy significantly reduced the number of natural sperms and total sperm count in experimental rats compared to the normal rats. It can also reduce sperm count and motility and decrease sperm viability in the kindled Wistar male rats [21].

On the other hand, a significant difference was observed in the group treated with S.edmondi essential oil compared to the epileptic control group in terms of sperm count, viability, and motility, which is due to the high antioxidant properties of this plant.The most common causes of infertility in men are their inability to produce enough healthy and active sperms and their reduced mobility [22]. Excessive production of reactive oxygen species (ROS) stops the cell cycle and increases the apoptosis process, thus reducing daily sperm production as well as the total number of sperms [23].

There is a steady decrease in sperm viability and progressive motility and a decrease in motility, which is associated with increased ROS level [24]. Epilepsy produces a variety of biochemical processes, including proteolysis and ROS emission, which can damage the fats and proteins and reduce antioxidant properties [25].Different doses of Ferollago angulata, a traditional herb in the west of Iran with high antioxidant power, significantly increase sperm parameters such as sperm count, motility, and survival, thus improving sperm parameters and enhancing spermatogenesis [26].

The protective effect of reproductive system degeneration on cyclosporine in male moths was also investigated by Satureja Khuzestanica[27].The resultsof Cao et al. showed that, the levels of important enzymatic and non-enzymatic antioxidants in Leydig cells decreased with an increase in oxidative stress, which reduced the synthesis and secretion of testosterone and an was an effective factor for spermatogenesis and dysfunction. As a result, there is a significant reduction in the number of epididymal sperm [28].Testosterone levels in the body play an important role in maintaining spermatogenesis, and lower levels of testosterone reduce sperm count [29].

The physiological effects of oxidative stress on male infertility have been investigated.It has been reported that oxidative stress causes endocrine disorders in the testicles and damagesthe testicular morphology [30]. Theantioxidant properties and role of Satureja Khuzestanicain infertility treatment have also been investigated [31]. The LH, FSH, and testosterone levels in the experimental epileptic group increased due to PTZ. A significant decrease was observed compared to the control group. However, there was a significant increase compared to the normal control group and the epileptic control grouponly in the highest dose (300 ppm).

The changes in follicle-stimulating hormone (FSH) in the study groups, whether in the normal rats or epileptic rats, increased slightly, which was not significant.Due to the production of free radicals by PTZand the induction of experimental epilepsy in the studied rats, a significant decrease was observed in the testosterone and lutein hormones compared to the control group. Due to the presence of antioxidant compounds, Satureja edmondi Briq significantly increased serum testosterone and lutein hormone 
compared to normal and epileptic control groups. The results are consistent with the results of a study that found that the kindling of Wistar male rats reduced serum testosterone and luteinizing hormonelevels, but did not change the serum levels of folliclestimulating hormone between groups [21].

An important factor in reducing serum testosterone is increased free radicals and oxidative stress. As a chronic neurological disorder, epilepsy can increase the active species of oxygen and the production of superoxide in the brain [32]. Studies have shown that epilepsy reduces serum LH concentrations and lowers LH,which consequently decreasesthe testosterone secretion [33].In the present study, serum testosterone levels decreased significantly in the epileptic group without treatment compared to the normal group. Different doses of plant extract with abundant antioxidant properties cause a significant increase in testosterone in Wistar male rats with oxidative diseases, thus improving and enhancing the fertility potential in these patients [16].

\section{Conclusion}

Epilepsy causes disorders in sperm parameters such as count, viability, and motility. It alsoimpairs the testicular tissue and lowersthe testosterone, LH, and FSH levels by damaging spermatogenesis and reducing total antioxidant capacity. The use of different doses of Satureja edmondiBriq increases the antioxidant power of testicular tissue and improves sperm quality and pathological changes caused by epilepsy-induced stress. Based on the results of this study, SaturejaedmondiBriq, which contains many antioxidant compounds such as thymol, gamma terpinene, $\mathrm{p}$-Cymene, alpha-Terpinene, acts as a natural antioxidant, removes the free radicals in the cell membrane, and protects lipid membrane against peroxidation. The antioxidant compounds of SaturejaedmondiBriq reduce the destructive effects of epilepsy on the reproductive process and potential.

\section{Abbreviations}

PTZ, pentylenetetrazol; WHO, World Health Organization; LH, luteinizing hormone; FSH, follicle-stimulating hormone; ppm, Parts per million

\section{Declarations}

\section{Ethics approval and informed consent}

The experiment protocol was approved by the ethics committee of animal research (IR.KUMS.REC.1398.977).

\section{Acknowledgments}

The Authors tanks Kermanshah brunch, Islamic Azad university, Kermanshah, Iran for funding the research project No. 1929804090001. 


\section{Consent for publication}

Not applicable.

\section{Availability of data and materials}

Data are available upon request from the corresponding author.

\section{Competing Interests}

The authors declare that they have no competing interests.

\section{Funding}

This work was supported by Kermanshah brunch, Islamic Azad University, Kermanshah, Iran for funding the research project No. 1929804090001.

\section{Authors'contributions}

Bohlouli designed the experiments and performed the experiments, mahmoodi analyzed the data and bohlouli wrote the manuscript with assistance from mahmoodi. They approved the final manuscript.

\section{Author details}

${ }^{1}$ Department of veterinary medicine ,College of Agriculture, Kermanshah Branch, Islamic Azad University, Kermanshah, Iran. ${ }^{2}$ Department of Biology, College of Basic Science, Kermanshah Branch, Islamic Azad University, Kermanshah, Iran.

\section{References}

1. Ashrafzadeh F, Tohidi H, Faraji E, AtaeiNakhaei A. Iranian Medicinal Plants and Intractable Epilepsy in Childhood: A Narrative Review. Rev Clin Med.2018; 5:33-36.

2. Velísek L, Nebieridze N, Chachua T, Velískov J. Anti-Seizure Medications and Estradiol for Neuroprotection in Epilepsy:The 2013 Update. Recent Patents on CNS Drug Discovery. 2013; 8: 2441.

3. Spencer D. Levetiracetam in Men With Epilepsy: Testosterone Is Left Alone But Sperm Count Is Paramount. Epilepsy Curr. 2017; 17: 99-100.

4. Iqbal khan O.Effects of Antiepileptic Drugs on Semen Quality, Sexual Function, and Sex Hormones in Men With Epilepsy. Springer plus. 2016; 5(1): 2070.

5. Atif M, Sarwar MR,Scahill S. The relationship between epilepsy and sexual dysfunction: a review of the literature. Horm Behav. 2013; 63: 267-277.

6. Isojärvi J. Disorders of reproduction in patients with epilepsy: antiepileptic drug related mechanisms. Seizure. 2008; 17(2):111-9. 
7. F Sefil F, Arık AE, Acar MD, Bostancı MO, Bagirici F, Kozan R. Interaction between carbenoxolone and valproic acid on pentylenetetrazole kindling model of epilepsy. Int J Clin Exp Med .2015; 8: 1050810514.

8. Geronzi U, LottiF, GrossoS. Oxidative stress in epilepsy. Expert Review of Neuro therapeutics. 2018; 18: $427-434$

9. Sadeghi E, Karami F, Etminan A.The Effect of Ferulagoangulata (Schlecht) Boiss Essential Oil on Stabilization of Sunflower Oil During Accelerated Storage. J. Food Process. Preserv. 2017; 41: e12745.

10. Sadeghi E, Mahtabani A, Etminan A, KaramiF.Stabilization of soybean oil during accelerated storage by essential oil of ferulagoangulataboiss. J Food Sci Technol.2016; 3:1199-1204.

11. Bohlouli S, Ghaedi G, Heydari M,Rahmani A, Sadeghi E. Effect of dietrary Persian oak (Quercusbrantii var.persica) fruit extract on survival growth per foromance, hematological and immunological parameters in rainbow trout, Oncorhynchus mykiss, fingerlings. Aquacult Nutr.2016; 22:745-751

12. Bohlouli S, Sadeghi E. Growth performance and haematological and immunological indices of rainbowtrout (Oncorhynchus mykiss) fingerlings supplemented with dietary Ferulagoangulata(Schlecht) Boiss. Acta Vet Brno. 2016; 85: 231-238.

13. Moradi, S., Sadeghi, E.Study of the antimicrobial effects of essential oil of Saturejaedmondi and nisin on Staphylococcus aureus in commercial soup. J. Food Process. Preserv. 2017;41(4): e13337

14. Mahmoodi G, Bohlouli S.Investigation the effectsof Saturejaedmondi on memory deficits induced by chemical kindling in male rats. J R PS 2020; In press.

15. Pourmotabbed A, Mahmoodi G, Mahmoodi S, MohammadiFarani A, Nedaei SE, PourmotabbedT .. Effect of central muscarinic receptors on passive- avoidance learning deficits induced by prentalpentylenetetrazol kindling in male offspring. Neuroscience. 2014; 279 : 232-237.

16. RostamiNassab G, Bohlouli S, GhanbariA. Therapeutic Effect of FerulagoangulataExtract on Reproductive Parameters and serum testosterone levels in Diabetic Male Rats. J R PS. 2018; 7(1), 1-8

17. Hamed S, Mohamed K, El-taher A, Hamed E, Omar H. The sexual and reproductive health in men with generalizedepilepsy: a multidisciplinary evaluation. Int J Impot.2006; 18: 287-295.

18. Abdollahi M, Salehnia A, Mortazavi SHR,Ebrahimi M, Shafiee A, Fouladian F, Keshavarz K, Sorouri S, Khorasani R, Kazemi A.Antioxidant, antidiabetic, antihyperlipidemic, reproduction stimulatory properties and safety of essential oil of SaturejaKhuzestanicain rat in vivo: a toxicopharmacological study. Med Sci Moni.2003; 9: 331-35.

19. Roste L S, Tauboll E, HaugenTB, BjOrnenak T, Sætre ER , Gjerstad L. Alterations in semen parameters in men with epilepsy treated with valproate or carbamazepine monotherapy. Euro j neurol. 2013;10:501-506. 
20. Isojarvi JI, Tauboll E, Herzog A. Effect of antiepileptic drugs on reproductive endocrine function in individuals with antiepileptic.CNS Drugs. 2005; 19: 207-23.

21. MehrabiNasabE ,Khazaei M , Khazaei S. The effect of pentylenetetrazol kindling induced epilepsy on hypogonadhormones and sperm parameters of rats. Arak Medical University Journal2010; 12: 105112.

22. Fukushima T, Hamada Y, Komiyama M, Matsuno Y, Mori C, Horii, I. Early changes in sperm motility, acrosome reaction, and gene expression of reproductive organs in rats treated with sulfasalazine. Reprod Toxicol. 2002; 23: 153-152.

23. Makker K, Agarwal A, Sharma R. Oxidative stress \& male infertility. Indian J. Med. Res. 2009; 129: 352-322.

24. -Kobayashi H, Gill-Guzman E, Mahran AM. Quality control of reactive oxygen species measurement by iuminal dependent chemiluminescence assay. J Androl. 2001; 22: 521-524

25. Cardenas-Rodriguez N, Huerta-Gertrudis B. Rivera-Espinosa L, Montesinos-Correa H, Bandala C, Carmona-Aparicio L, Coballase-Urrutia E. Role of Oxidative Stress in Refractory Epilepsy: Evidence in Patients and Experimental Models. Int J MolSci 2013 ; 14: 1455-1476.

26. Bohlouli S, Rostaminasab G. Effect of Hydroalcoholic Extract of Ferollagoangulata on Sperm and Testosterone Indicesin Male Rats.sjimu .2019; 3:47-55.

27. -Najafı G, Farokhi F, ShalizarJalali A, Akbarizadeh Z. Protection against cyclosporine-induced reprotoxicity by Saturejakhuzestanica essential oil in male rats. Int J Fertil Steril. 2016; 9: 548-57.

28. Cao L, Leers-Sucheta S, Azhar S. Aging alters the functional expression of enzymatic and nonenzymatic anti-oxidant defense systems in testicular rat Leydig cells. The Journal of steroid biochemistry and molecular biology. 2004; 11: 21-22

29. -Zhang Z, Liao L, Moore J, Wu T,Wang Z. Antioxidant Phenolic Compounds from Walnut Kernels( Juglansregia L.). Food Chemist. 2009; 113: 160-5.

30. Pook M, Tuschen-Caffier B, Krause W. Is infertility a risk factor for impairedmale fertility? Human Reproduction . 2004; 19: 954-959.

31. Safarnavadeh T, Rastegarpanah M. Antioxidants and infertility treatment, the role of SaturejaKhuzestanica: A mini-systematic review. Iran J Reprod Med. 2011; 9: 61-70.

32. Omrani A, Ghadami MR, Fathi N,Tahmasebian M, Fatholahi Y, Touhidi A. Naloxane improve impairment of spatialperformance induced by pentenyletetrazol kindeling in rats. Neuroscience. 2002; 145:124-31.

33. VeliskovaJ, DeSantisKA. Sex and Hormonal influences on Seizures and Epilepsy. HormBehav. 2013; 63: $267-277$.

\section{Figures}




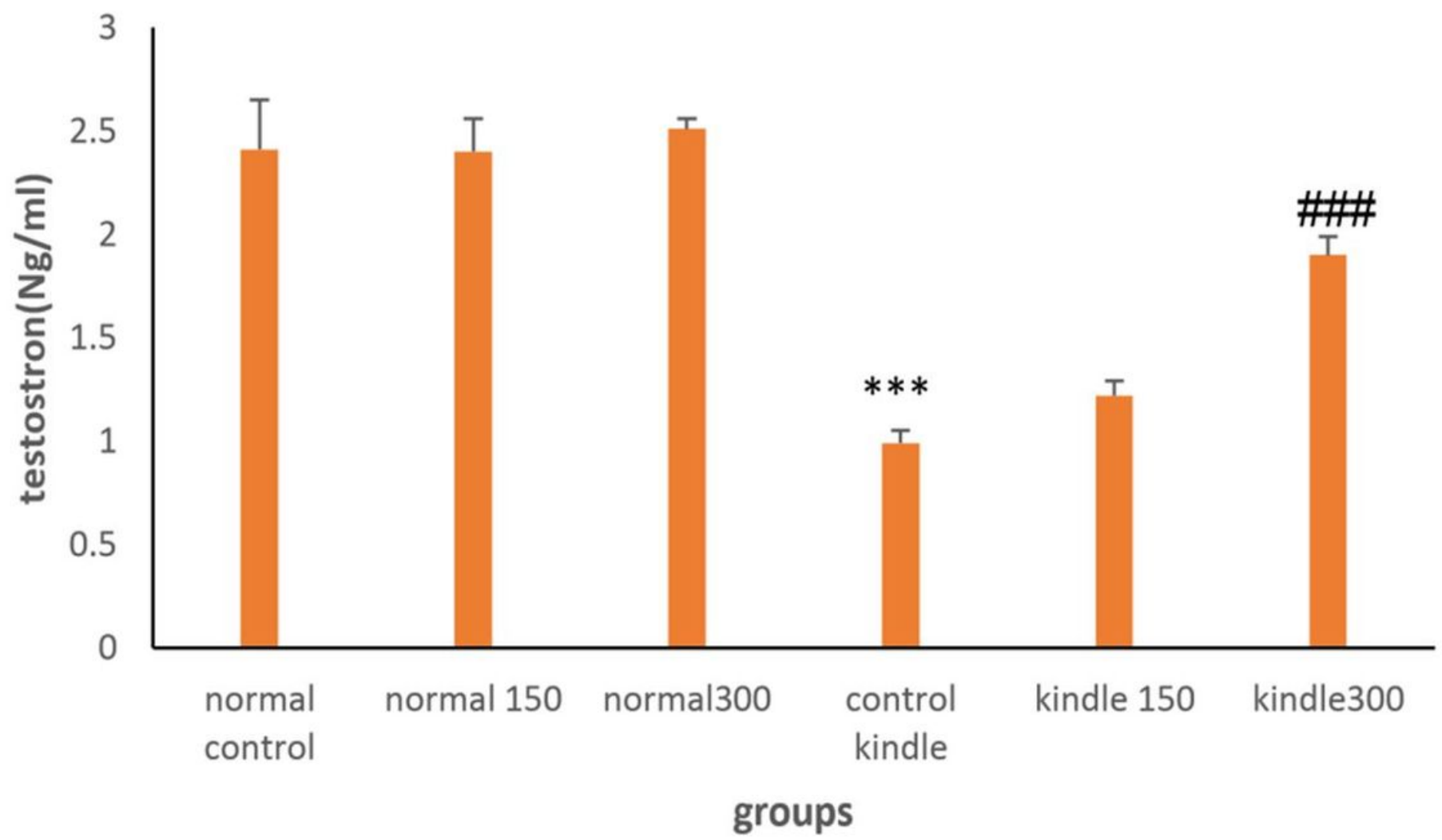

Figure 1

The effect ofSaturejaedmondi Briq essential oil on testosterone $(\mathrm{ng} / \mathrm{ml})$ treatment groups included: normal control, normal groups with 150 and $300 \mathrm{ppm}$ of S. edmondi essential oil, kindle control, kindle groups with 150 and $300 \mathrm{ppm}$ of S.edmondi essential oil. $\star \star \star ~ p \leq 0.001$ : Statistical difference with control normal group \#\#\# $\mathrm{p} \leq 0.001$ : Statistical difference with kindle control group 


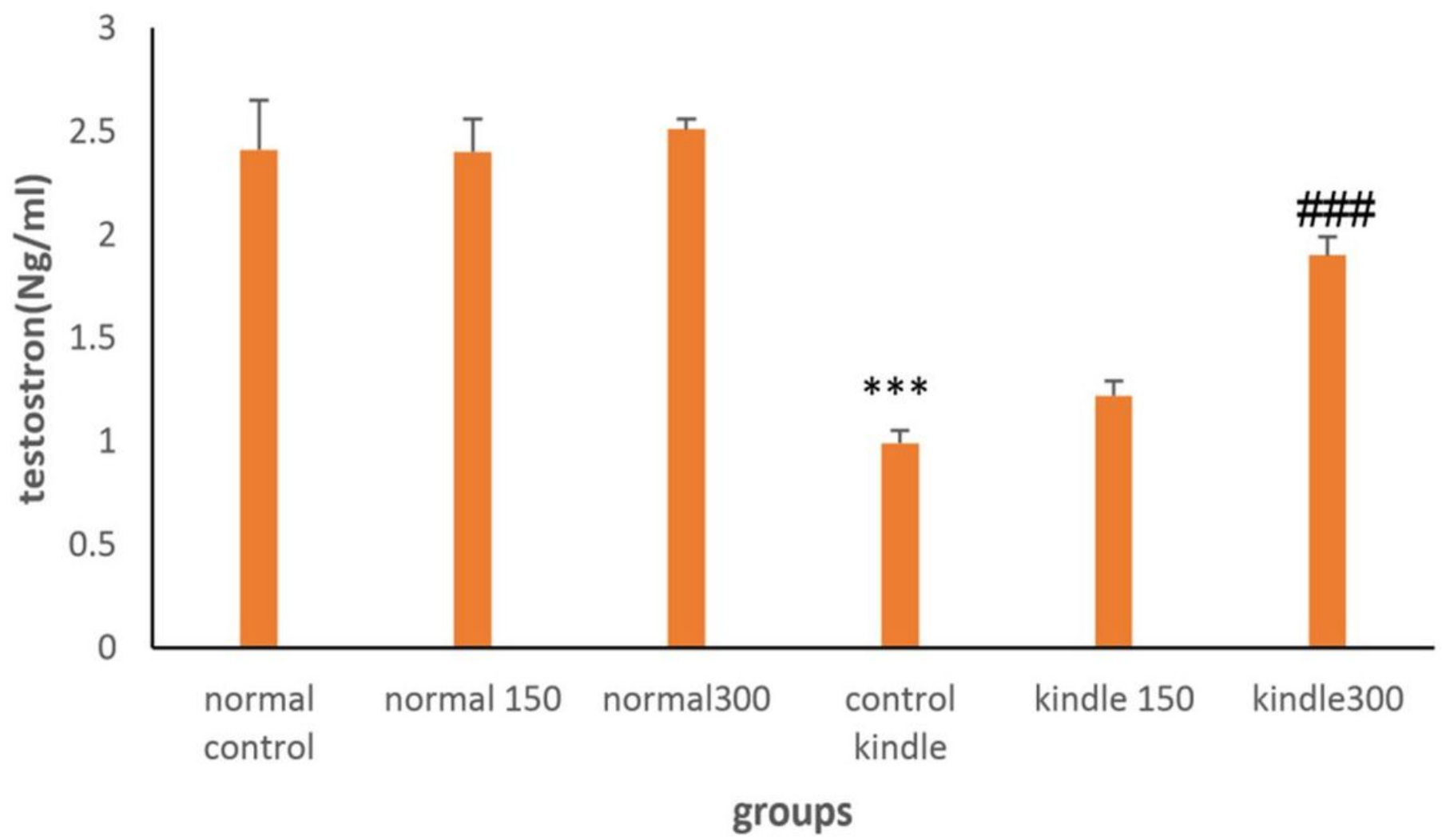

Figure 1

The effect ofSaturejaedmondi Briq essential oil on testosterone $(\mathrm{ng} / \mathrm{ml})$ treatment groups included: normal control, normal groups with 150 and $300 \mathrm{ppm}$ of S. edmondi essential oil, kindle control, kindle groups with 150 and $300 \mathrm{ppm}$ of S.edmondi essential oil. $\star \star \star ~ p \leq 0.001$ : Statistical difference with control normal group \#\#\# $\mathrm{p} \leq 0.001$ : Statistical difference with kindle control group 


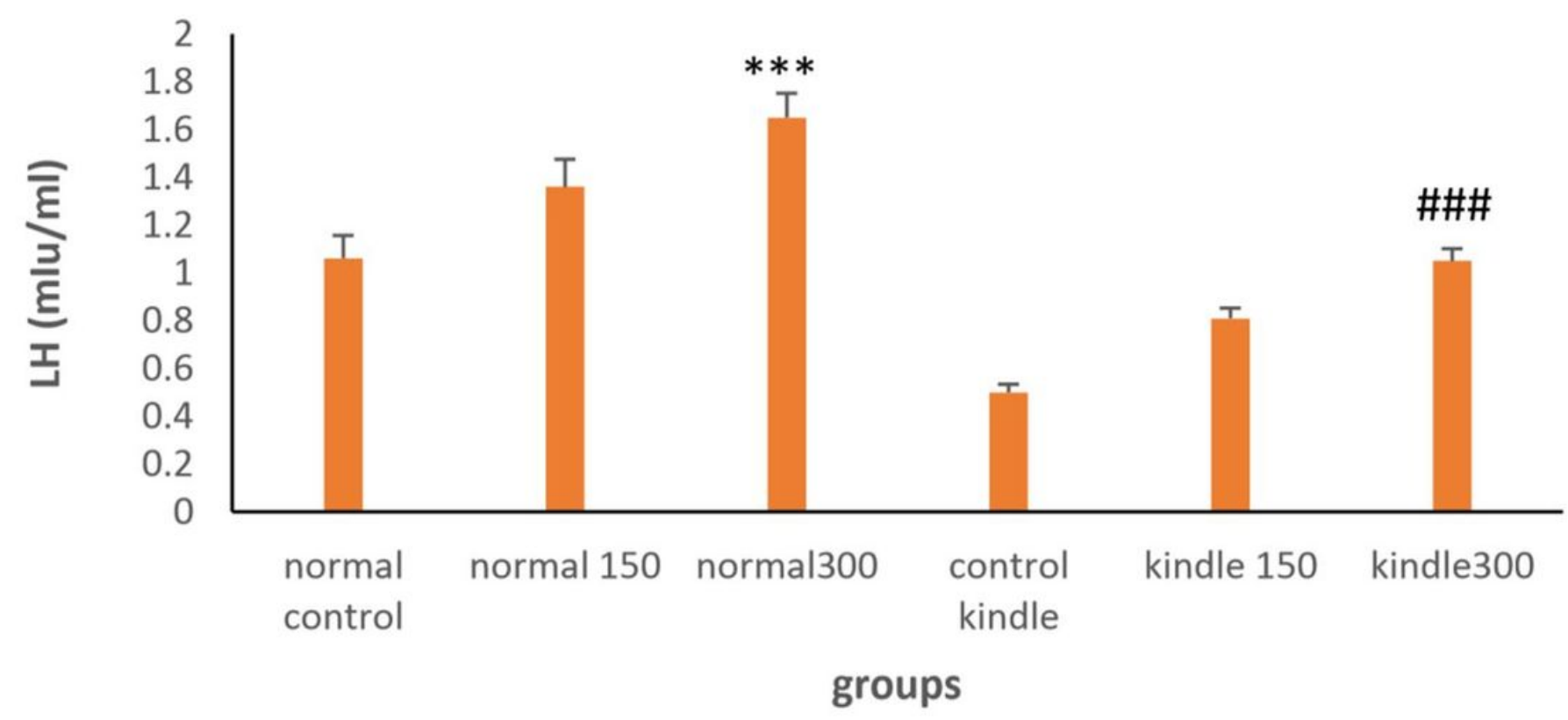

Figure 2

The effect ofSatureja edmondi Briq essential oil on $\mathrm{LH}(\mathrm{mlu} / \mathrm{ml})$ in treatment groups included: normal control, normal groups with 150 and 300 ppm of Satureja edmondi Briq essential oil, kindle control, kindle groups with 150 and 300 ppm of Satureja edmondiBriq essential oil. $* \star \star ~ p \leq 0.001$ : Statistical difference with control normal group \#\#\# $\mathrm{p} \leq 0.001$ : Statistical difference with kindle control group

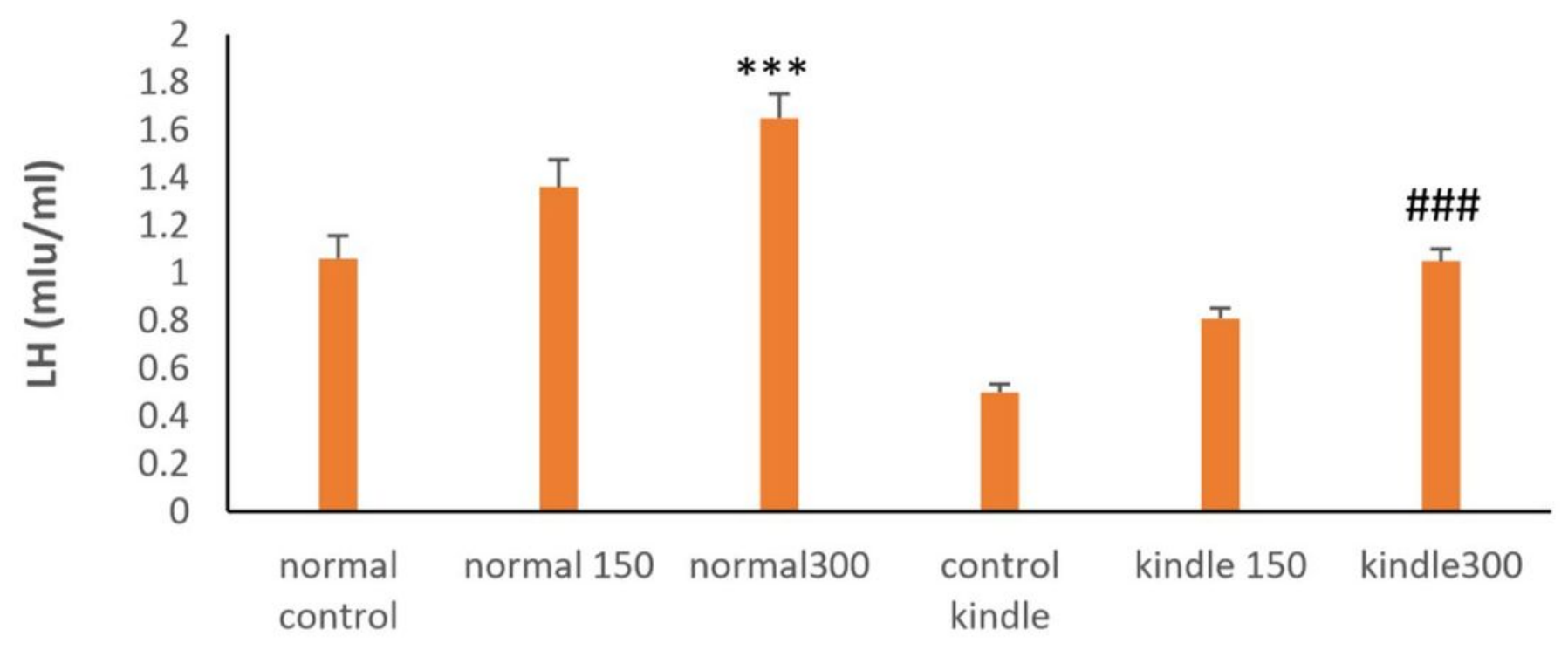

groups

Figure 2 
The effect ofSatureja edmondi Briq essential oil on $\mathrm{LH}(\mathrm{mlu} / \mathrm{ml})$ in treatment groups included: normal control, normal groups with 150 and 300 ppm of Satureja edmondi Briq essential oil, kindle control, kindle groups with 150 and 300 ppm of Satureja edmondiBriq essential oil. $* \star \star p \leq 0.001$ : Statistical difference with control normal group \#\#\# $p \leq 0.001$ : Statistical difference with kindle control group

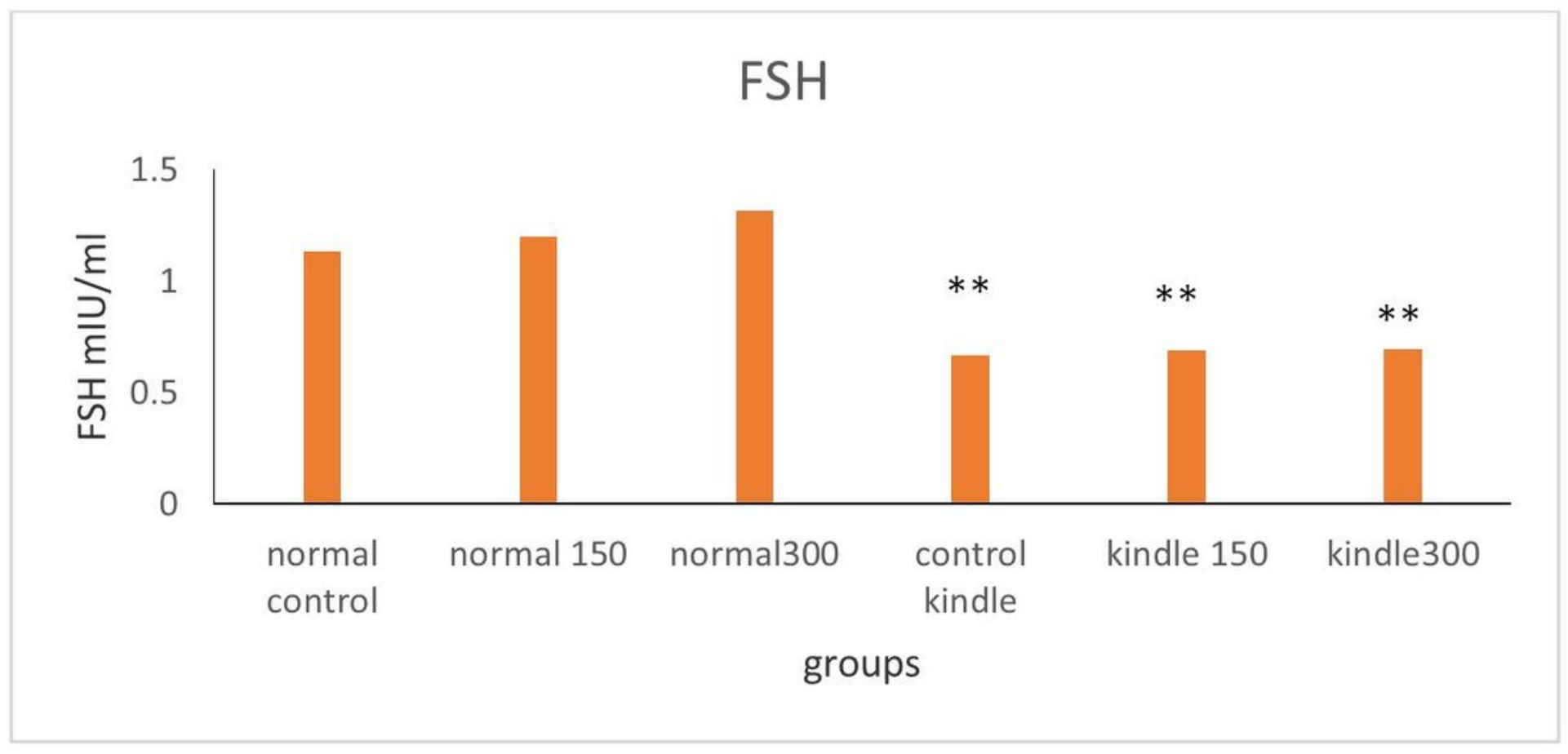

\section{Figure 3}

The effect of Satureja edmondi Briq essential oil on $\mathrm{FSH}(\mathrm{mlu} / \mathrm{ml})$ in treatment groups included: normal control, normal groups with 150 and $300 \mathrm{ppm}$ of S. edmondi Briq essential oil, kindle control, kindle groups with 150 and 300 ppm of S. edmondi Briq essential oil. ${ }^{* *} p \leq 0.01$ : Statistical difference with control normal group 


\section{$\mathrm{FSH}$}

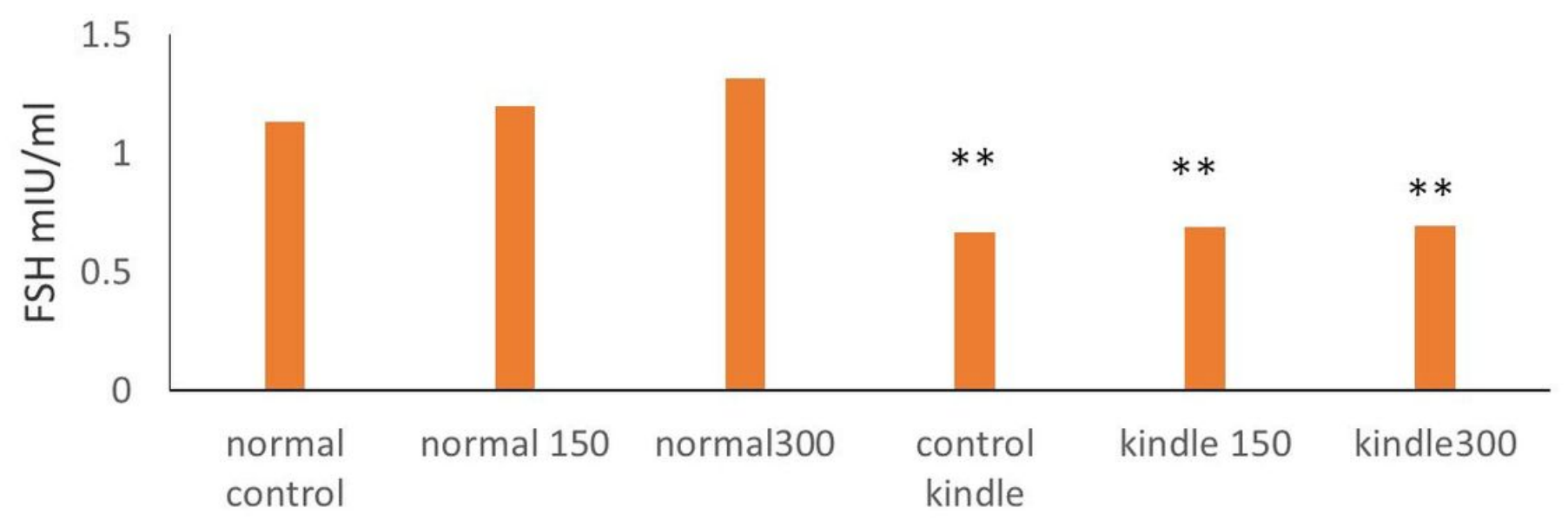

groups

Figure 3

The effect ofSatureja edmondi Briq essential oil on $\mathrm{FSH}(\mathrm{mlu} / \mathrm{ml})$ in treatment groups included: normal control, normal groups with 150 and $300 \mathrm{ppm}$ of $\mathrm{S}$. edmondi Briq essential oil, kindle control, kindle groups with 150 and 300 ppm of S. edmondi Briq essential oil. ** $p \leq 0.01$ : Statistical difference with control normal group 